\title{
Agency is realized by subpersonal mechanisms too
}

\author{
Neil Levy \\ Department of Philosophy, Macquarie University, Sydney, NSW, Australia. Uehiro \\ Centre for Practical Ethics, University of Oxford, Suite 8, Littlegate House, 16/17 Ebbes \\ St., OX1 1PT, United Kingdom. \\ neil.levy@philosophy.ox.ac.uk
}

\begin{abstract}
John Doris argues that when behaviors are caused by processes that we would not endorse, our agency is defeated. I argue that this test for defeaters is inappropriate. What matters is not what we would but what we should endorse. The subpersonal mechanisms he identifies as defeaters enable us to track and respond to reasons. They realize agency, rather than defeating it.
\end{abstract}

There is, as John Doris (2015) emphasizes, extensive evidence that human agents often act in ways that are influenced by mechanisms that respond to features of the world without the agent being aware of the relevant mechanisms or of how they respond to the features. Often, too, these mechanisms work in ways that the agents would not endorse on reflection. Doris suggests that this evidence poses a major problem for the justified ascription of moral responsibility to agents like us. Our vaunted capacity to reflect, deliberate, and make decisions is threatened by the existence of what he calls 'defeaters.' Talking to Ourselves is a systematic response to this challenge. The first part of the book identifies the problem; the second offers a solution to it. In this review I will focus on the first half. While there is much to recommend the account of agency Doris develops in the second, I will suggest that the problem it aims to solve is largely illusory.

A defeater is a cause of a decision or action that would not be recognized as responding to reasons in its favor by the person, were she aware of its influence (pp. 645). Consider the ballot order effect, for example. There is extensive evidence, cited by Doris, that being at the top of the ballot gives a candidate an electoral advantage. But people wouldn't recognize being at the top of the ballot as a genuine reason to favor one candidate over another. When their choice of candidate is influenced by ballot order, it is influenced by mechanisms the workings of which the person would not endorse if she became aware of them. When "the causes of her cognition or behavior would not be 
recognized by the actor as reasons for that cognition or behavior, were she aware of these causes at the time of performance, these causes are defeaters" (ibid.). It is a defeater of what Doris calls agency (which he understands as a capacity of agents to act such that their actions reflect their values), and therefore of moral responsibility.

Many of the processes causally involved in our decisions and actions satisfy Doris's definition of defeater; were we aware of them, we would not endorse them. But the standard provided by Doris's test is not the appropriate one to identify genuine defeaters of agency and responsibility. It does not matter, for these purposes, what we would endorse. What matters is what we should endorse. Many of the processes that Doris's tests identify as defeaters of agency are better understood as helping to realize agency, whether or not we would endorse them.

On the most plausible account, or family of accounts, morally responsible agency consists essentially in the capacity to recognize and respond to reasons, including moral reasons (Fischer \& Ravizza 1998; McKenna 2017). In fact, Doris himself seems to assume such an account, at least as a necessary condition of moral responsibility, which is why he worries that defeaters are such a serious problem for us. They defeat agency by bypassing or overwhelming our capacity to recognize and respond to reasons (p. 52). But there is no reason to identify the capacity to recognize and respond to reasons with a set of processes that we would endorse were we to become aware of them. What matters is whether the processes actually enable us to track and respond to reasons, not whether we would endorse them were we aware of them. And very many, perhaps the overwhelming majority, of the processes that Doris identifies as defeaters are better seen as realizers of our agency than as defeaters of it.

Many of the processes that are supposed to be defeaters of agency are evolved dispositions. We have these dispositions (to prefer the first presented candidate, for instance) because they were adaptive in our ancestral environment. And in the main they were adaptive because they enabled us to track and respond to reasons better than we would have done were we to rely on slow, effortful, resource intensive, domain-general reasoning. While we live in vastly different environments today, a large proportion of these processes continue to track reasons. They do so whether or not we would endorse them. 
Consider, for example, our disposition to prefer the default option when choosing the settings for everything ranging from insurance policies through to organ donation (Johnson \& Goldstein 2003). Perhaps we would not endorse this disposition on reflection. But the disposition is likely adaptive, for a range of reasons. First, the default option may be the default for a reason; that is, it may be because it is the best option (or at minimum a satisfactory option) for most people that it is the default. Its selection as the default may reflect its endorsement by those who designed the policy (who are often in a better position to pick the best option than the consumer). Of course, defaults may be chosen arbitrarily or for bad reasons, but if they remain the default over time, the agent can often be confident that it is not a bad choice (by the standards prevailing in her group). If a very large number of people have faced the same decision before her, and the default has remained the default over time, then it is unlikely to be contrary to mainstream prevailing values. Here is one point at which the socially embedded conception of agency Doris defends in the second half of the book indeed provides part of the solution to the problem he addresses: the processes that he thinks of as defeaters are often designed to rely on features of the social environment.

Whether designed by nature or acquired in development, the suite of subpersonal mechanisms that cause our behavior are typically adaptive, and typically they are adaptive because they enable us to track and to respond to reasons. Very often, regardless of whether we would endorse them, they do a better job of tracking reasons than the kinds of processes we would endorse on reflection (like slow, effortful, conscious deliberation). They may do a better job because they are fast and frugal, allowing for good enough decision making in conditions in which speed is at a premium or the expected marginal benefit of engaging in effortful deliberation is too small to justify the expenditure of time and resources needed for effortful deliberation. Often, however, they do a better job than conscious deliberation, were the agent to take the time to engage in it. When the data is noisy, for instance, we often do better to employ a simple heuristic (of the kind embodied in subpersonal mechanisms) than to employ conscious deliberation, because tracking a few cues yields better results (Gigerenzer 2008). Even under conditions conducive to deliberation (when the problem is tractable computationally, deliberation is capable of outperforming subpersonal mechanisms and the decision is 
important enough to justify the investment), conscious deliberation may often lower decision quality relative to the employment of heuristics (Wilson \& Schooler 1991). People may endorse conscious deliberation and reject subpersonal processes, but the second may do just as good, or better, a job at tracking reasons and thereby enabling agency.

Even when subpersonal mechanisms cause us to make choices in ways that fail to track reasons, they typically do not bypass our agency. Consider the ballot order effect again. While sometimes candidate order conveys information about the quality of the candidate (Marcinkiewicz 2014), often it does not. In many electoral systems, voters face a choice between candidates assigned ballot order by lot or alphabetically. Random allocation does not correlate with candidate quality, and alphabetical order is unlikely to (though there might be very weak indirect effects; perhaps having a name with an initial letter that occurs early in the alphabet leads to more opportunities to speak in school environments, for example). It is noteworthy, though, that ballot order effects make a significant difference to the choices of two groups of voters: low information voters and those who are nearly indifferent between options about which they are knowledgeable. Now, while the ballot order effect can be expected to make a difference to the choices of many people in these two groups, it does not thereby bypass their agency (that is their capacity to express their values in their actions). For those who are indifferent between the option chosen and another, both of which they're informed about, each choice expresses their values just as well as the other, so the effect does not make a difference between expression and its absence. The choices of low information voters may not express their values, but the primary reason for this is not because the choice is influenced by ballot order: it is because they don't know enough for their choice to express their values. The choice is not a worse expression of their values than the one they would make were they to reflect more. Low information voters susceptible to ballot order effects are also indifferent between options because they don't know enough about them to make a choice. When the ballot order effect influences them to make a choice, that choice is not a worse expression of their agency than one they might have chosen had they reflected. 
Of course, the subpersonal mechanisms that orient us toward some considerations and away from others sometimes lead to suboptimal behaviors. Such mechanisms may fail to track reasons because a mechanism that was adaptive (by tracking reasons) in the environment of evolutionary adaptiveness may no longer function to track reasons in our very different environment. How often such mismatches between environments cause the bypassing of agency is an open question. The extent of bypassing is limited by two factors. First, social forces often work to ensure that our dispositions to choose do not depart very significantly from satisfactory choice by altering the environments in which we choose (again, a default option that is not satisfactory for most people will likely be culturally selected against). Second, subpersonal mechanisms are not deployed blindly; rather, they are more likely to be deployed when they are appropriate (Todd \& Gigerenzer 2007). Subpersonal mechanisms may also simply misfire. Such a mechanism may still appropriately be regarded as partially constitutive of morally responsible agency: conscious deliberation, too, is prone to misfiring in unpropitious circumstances.

Doris's principal target in Talking to Our Selves is the view he calls reflectivism. Reflectivism is the view that cognition and behavior is agential only when it is preceded or accompanied by reflection on how to behave. As Doris argues, reflectivism is hard to square with the general drift of the evidence from cognitive science: if only actions that are appropriately ordered by reflection count as instances as morally responsible agency, then there are precious few instances of such agency. The conflict between reflectivism and the view urged here, according to which agency is pervasively realized by subpersonal mechanisms that are opaque to introspection, may be reduced by the recognition that consciousness is genuinely important for flexible response in novel situations. It is important, not because conscious deliberation is powerful, but because consciousness is the gateway to global availability to the subpersonal mechanisms that realize agency (Levy 2014). Behavior does not need to be ordered by reflection to be agential. Rather, the suite of mechanisms that constitute us also make us genuinely reasons-responsive agents.

Acknowledgements: Partially supported by a grant from the Wellcome trust (WT104848/Z/14/Z). 


\section{References}

Doris, J.M. (2015). Talking to Our Selves: Reflection, Ignorance, and Agency. Oxford University Press.

Fischer, J.M. \& Ravizza, M. (1998). Responsibility and Control: A Theory of Moral Responsibility. Cambridge University Press.

Gigerenzer, G. (2008). Why heuristics work. Perspectives on Psychological Science 3: 20-29.

Johnson, E. J. \& Goldstein, D. (2003). Do Defaults Save Lives? Science 302 (5649): 1338-1339.

Levy, N. (2014). Consciousness and Moral Responsibility. Oxford University Press.

Marcinkiewicz, K. (2014). Electoral contexts that assist voter coordination: Ballot position effects in Poland. Electoral Studies 33: 322-334.

McKenna, M. 2017.Reasons-responsive theories of freedom. In Timpe, K. Griffith, M. \& Levy, N. (eds). The Routledge Companion to Free Will (pp. 27-40). Routledge.

Todd, P.M. \& Gigerenzer, G. (2007). Environments That Make Us Smart Ecological Rationality. Current Directions in Psychological Science 16: 167-171.

Wilson, T. D., \& Schooler, J. W. (1991). Thinking too much: Introspection can reduce the quality of preferences and decisions. Journal of Personality and Social Psychology 60: 181-192. 